\title{
Trus Biopsy and Octogenarians- a Change in Management?
}

\author{
Goonewardene $\mathrm{SS}^{1 *}$, Persad $\mathrm{R}^{2}$ and Gillatt $\mathrm{D}^{3}$ \\ ${ }^{1}$ The Royal Free Hospital and UCL Medical School, UK \\ ${ }^{2}$ North Bristol NHS Trust, England \\ ${ }^{3}$ McQuarrie University, Sydney
}

Submission: May 27, 2016; Published: October 12, 2016

*Corresponding author: Goonewardene SS, The Royal Free Hospital and UCL Medical School, London, UK.

\section{Introduction}

TRUS biopsy (Trans rectal Ultrasound guided biopsy) of the prostate is recommended for the histological confirmation of prostate cancer in patients with raised PSA and/or clinically suspicious digital rectal exam, prior to treatment. In the era of multi parametric MRI and trans perineal template biopsies, one could argue TRUS biopsies are no longer the gold standard. An increasing number of octogenarians are being referred with elevated PSA, the role of TRUS biopsy in these patients is debatable.

NICE guidance suggests TRUS biopsy is required in presence of an abnormal clinical examination and PSA, but do not specify an age limit. NICE guidance does state management can be initiated, without having a prior biopsy, on clinical suspicion of a significant cancer burden. Additionally, no literature covers this topic for the over 80 age group.

Keywords: TRUS Biopsy; Prostate Cancer; Elderly; Octogenarian

\section{Aims and objectives}

We aim to reviewed use of TRUS biopsy in the over 80 age group at Guys Hospital, Kings College London and North Bristol NHS Trust over the past 3 years. Notes and electronic records were examined for clinical stage, Gleason grade, overall risk stratification, management, patient outcomes, and whether biopsy ultimately changed the management plan.

\section{Results}

114 patients over the age of 80 years underwent TRUS biopsy over the last 3 years. The mean age of octogenarians undergoing TRUS biopsy was 82.8 years (range $80-90$ years). Prior to biopsy, 18 patients had a benign feeling DRE $(15.8 \%, 75 \%$ of these patients had cancer), the rest ( 96 patients, $84.2 \%$ ) were clinically suspicious for malignancy (76.4\% of these had cancer).
$39(34 \%)$ patients went onto watchful waiting after biopsy. $66 \%$ of patients had non-surgical treatment hormones/ radiotherapy (41 patients) or brachytherapy (brachytherapy). No patients were recorded as having complications.

The average Charlson Comorbidity weighted index was 2.48 with a range from 1-8. With the age adjusted score this increased to 6.34 (range 4-13). One year predicted survival from this score would be $67.9 \%$ with a range from $63-81 \%$.

\section{Discussion}

Firstly, we are biopsying a cohort of adults, which have a diagnosis of cancer present, in the majority of cases, clinically but were very fit. Whilst, in some cases, patients went onto to have curative hormones/ radiotherapy, others were commenced on hormone therapy. No patients went onto trial or study protocols.

In a large proportion of these patients treatment was indicated albeit with non-surgical means because of stage of disease and fitness. These results demonstrate TRUS biopsy is justified in appropriately selected 80 year olds in enabling stratification of the disease.

Without biopsy a significant proportion may have been treated unnecessarily (either abnormal DRE patients whose biopsies were negative or biopsy positive patients who had low risk disease). Additionally patients who turned out to have high risk disease and benefited from hormones and radiotherapy may have been overlooked. Ageism would appear to have no place in the management of (healthy) over 80 year olds.

More critically, those put on none invasive curative treatment as hormones and radiotherapy or brachy therapy are cured, with no complications or PSA relapse. This should perhaps be considered more for this age group provided they are fit. Additionally, very few on hormones have progression of disease, with no side effects recorded. 


\section{Conclusion}

We conclude, whilst TRUS biopsy gives diagnostic advantages in the younger age groups, it may not be appropriately used in the over 80s. More none invasive curative treatments such as hormones radiotherapy or brachytherapy should also be considered.

\begin{tabular}{l} 
Your next submission with JuniperPublishers \\
will reach you the below assets \\
- Quality Editorial service \\
- Swift Peer Review \\
- Reprints availability \\
- E-prints Service \\
- Manuscript Podcast for convenient understanding \\
- Global attainment for your research \\
- Manuscript accessibility in different formats \\
( Pdf, E-pub, Full Text, Audio) \\
- Unceasing customer service \\
Track the below URL for one-step submission \\
http://juniperpublishers.com/online-submission.php \\
\hline
\end{tabular}

